\title{
The Phytochemical screening and the effects of methanolic extract of Phyllanthus amarus leaf on the Biochemical parameters of Male guinea pigs.

\author{
${ }^{1}$ OBIANIME, A.W; ${ }^{2} \mathrm{UCHE}$, F.I
}

${ }^{I}$ Department of Pharmacology University of Port Harcourt. ${ }^{2}$ Department of Pharmacognosy University of Port Harcourt, Nigeria. Email: uchefideliaijeoma@yahoo.com8037066891

\begin{abstract}
The phytochemical screening and the effects of the methanolic extracts of the leaves of Phyllanthus amarus on some biochemical parameters of male Guinea pigs were investigated. Phytochemical investigations revealed the presence of flavonoids, tannins, alkaloids, terpenoids, steroids, saponins and cardiac glycosides. The methanol extract of Phyllanthus amarus leaves $(50-800 \mathrm{mg} / \mathrm{kg})$ caused a statistically significant $(\mathrm{P}<$ 0.05 student's t-test) decrease in the levels of total cholesterol, AST, ALT, urea, uric acid, total protein, prostatic, alkaline, and acid phosphatases. The highest reduction effect was obtained with uric acid at $400 \mathrm{mg} / \mathrm{kg}$ of P.amarus extract while the least effect was observed in total cholesterol. These effects were dose- and time- dependent. This shows that the leaves of $P$.amarus have hepatoprotective, nephroprotective and cardio protective properties. The study therefore, supports the claim on the use of the aerial part of this plant by traditional medicine practitioners as a hepatoprotective agent. Although further studies need to be done to investigate the contribution of the seeds of this plant as a hepatoproctective and nephroprotective agent and to isolate, identify and characterize the active principles in the leaf extracts of this plant. @ JASEM
\end{abstract}

Phyllanthus amarus Schum (Family Euphorbiaceae) is a widely distributed small erect, tropical annual herbal shrub whose stem has green capsule, and grows upto $10-50 \mathrm{~cm}$ high and blooms with flowers with 5 white sepals and apical acute anther. The fruit has green capsules, and smooth and fruiting pedicels. The seeds are longitudinally rogues. It is locally called Iyin-olobe (Yoruba, south- west Nigeria) (Adeneye et al, 2006) or kidney stone plant. In traditional medicine, it is used for its hepatoprotective, anti-diabetic, antihypertensive, analgesic, anti-inflammatory and antimicrobial properties (Adeneye et al., 2006). The plant is also used in the treatment of stomach disorders, skin diseases and cold (Kokwaro, 1976, Iwu,1993). It has anti-diarrhea effect (Odetola and Akojenu 2000). Its anti- viral activity against hepatitis $B$ virus has been established (Thyagarajan et al., 1988; Meixa et al 1995); anti-carcinogenic(Joy and kutten, 2000) and antimutagenic activities (Joy and Kutten, 1998).It also has anti- nociceptive and anti- inflammatory activities (kassuya et al, 2003), antidiabetic and antilipidemic potentials (Adeneye et al ,2006).

So far, there is limited information on the effects of Phyllanthus amarus on the biochemical parameters such as: uric acid, total protein, total cholesterol, AST, ALT, creatinin, urea, alkaline, acid and prostatic phosphatases of male guinea pigs. Also there has been claim on the use of the aerial parts of Phyllanthus amarus as hepatoprotective agent by traditional medicine practitioners. Based on this claim, this study, for the first time intend ascertain this claim and to provide a scientific information on the efficacy of Phyllanthus amarus leaf extract as a hepatoprotective agent and its effects on the biochemical parameters of male guinea pigs.

${ }^{*}$ Corresponding author: Obianime, A.W

\section{MATERIALS AND METHODS}

All the chemicals used were of analar grade.

\section{Plant Material}

The leaves of Phyllanthus amarus were collected from the local garden within the premises of University of Port Harcourt in June 2008. The plant was identified and authenticated by Edwin Nwosu of department of Botany herbarium, University of Port Hacurt .Voucher specimen was maintained at the Herbarium.

The fresh leaves collected were air- dried for 10days, until a constant weight was attained.

\section{Preparation of Extract}

The dried leaves of Phyllanthus amarus were pulverized. The crude powder $(100 \mathrm{~g})$ was extracted with methanol using Soxhlet extraction method. The solid residue obtained $(30.0 \% \mathrm{w} / \mathrm{w})$ was kept in a capped container in a refrigerator. Different concentrations of the extract used $(50,100,200,400$ and $800 \mathrm{mg} / \mathrm{kg}$ ) were reconstituted from this stock.

\section{Experimental animals}

The male guinea pigs were collected from the animal house of University of Port Harcourt. The weight of the animals ranges from $300-600 \mathrm{~g}$. The animals were allowed to acclimatize with the new environment (7) before the experiment. They were housed in a cage of five animals per cage and were adequately feed throughout the experiment. The time- dependent study lasted for 28 days while dose- dependent took 4 days.

\section{Phytochemical screening}

Chemical tests were carried out on the methanolic extracts and on the powdered specimens using standard procedures to identify the constituents (Trease and Evans, 1989; Harborne, 1998) by 
characteristic colour changes as described by Sofowara, (1993); Odebedy and Sofowara, (1978). Briefly, formation of brownish green coloration on addition of 3 drops of ferric chloride to sample confirmed presence of tannins; Formation of yellow coloration which disappears on standing when $5 \mathrm{ml}$ of dilute ammonia solution and concentrated sulphuric acid were added sequentially to portion of the extract confirms the presence of flavonoids; presence of steroids was confirmed by colour change from violet to blue on addition of $2 \mathrm{ml}$ acetic anhydride and $2 \mathrm{ml}$ sulphuric acid to $0.5 \mathrm{~g}$ plant extract; Terpenoids were confirmed by formation of reddish brown colouration of the interface on addition of $2 \mathrm{ml}$ chloroform and concentrated sulphuric acid, $3 \mathrm{ml}$ to $5 \mathrm{ml}$ of the extract; saponins were confirmed in the plant by the frothing test; cardiac glycosides were confirmed by formation of brown ring of interface on addition of $2 \mathrm{ml}$ glacial acetic acid containing 1 drop of ferric chloride solution and $1 \mathrm{ml}$ concentrated sulphuric acid; presence of alkaloids were confirmed by Dragendorff reagent which formed a reddish brown precipitate with the sample.

\section{Evaluation of Biochemical parameters}

The animals were divided into ten groups of five animals each. Group 1-5 were used for time dependent studies for a period of 28 days. While group 6-10 were used for dose- dependent studies. The animals from group 6-10 were administered different doses of the extract $(50-800 \mathrm{mg} / \mathrm{kg} /$ day) for 96 hours after which they were sacrificed. While the group 1-6 animals were administered a fixed dose of the extract $(400 \mathrm{mg} / \mathrm{kg} /$ day $)$ over a period of 7,14 , 21,28 days respectively. At the end of each treatment period, the

animals from different groups were anesthetized with diethyl ether. The blood samples were collected by cardiac puncture with $21 \mathrm{G}$ needle fixed on $5 \mathrm{ml}$ syringe, for serum liver enzyme makers and blood enzyme assays. These were assayed using Randox Diagnostic kits (Adeneye et al 2006), Phenophthalin method (Babson et al 1966) and colorimetric method
(Fisherman and Davidson, 2006).Sample serum was separated from the cells, centrifuged at 3400r for 10 minutes and used for the assays.

\section{Statistical analysis}

Results were expressed as mean \pm standard error of mean (SEM) of five observations. Statistical analysis of data was performed using student t-test. P-values of less than 0.05 were considered significant.

\section{RESULTS AND DISCUSSION}

Phytochemical screening revealed the presence of steroids, flavonoids, alkaloids, steroids, cardiac glycosides, terpenoids, tannins and saponins (table1). The flavonoids, as an anti-oxidant in this plant may contribute to the effects of this plant as hepatoprotective and nephroprotective, antimicrobial, anti-inflammatory, and anti-carcinogenic effect (Joy and kuttan, 1998; Iwu, 1993; Kasuya et al., 2003; Adeneye et al., 2006). Alkaloids in this plant may be responsible for its effects as anti-malaria, analgesic properties and its use in treatment of stomach disorder. This is consistent with the past works of Okwu and Josiah, (2006). Alkaloids and their synthetic derivatives are used as basic medicinal agents for their antispasmodic and bactericidal effects (Stray, 1998; Okwu, 2004).Tannins have astringent properties, hastens the healing of wounds and inflamed mucous membranes (Okwu and Josiah, 2006).

Table 1: Phytochemiacal Screening

\begin{tabular}{ll}
\hline Phytochemicals & P.amarus \\
\hline Alkaloids & + \\
Flavonoids & + \\
Terpenoids & + \\
Saponins & + \\
Tannins & + \\
steroid & + \\
Resins & - \\
\hline Cardiac glycosides & + \\
\hline & \\
$+=$ present & \\
$-=$ absent &
\end{tabular}



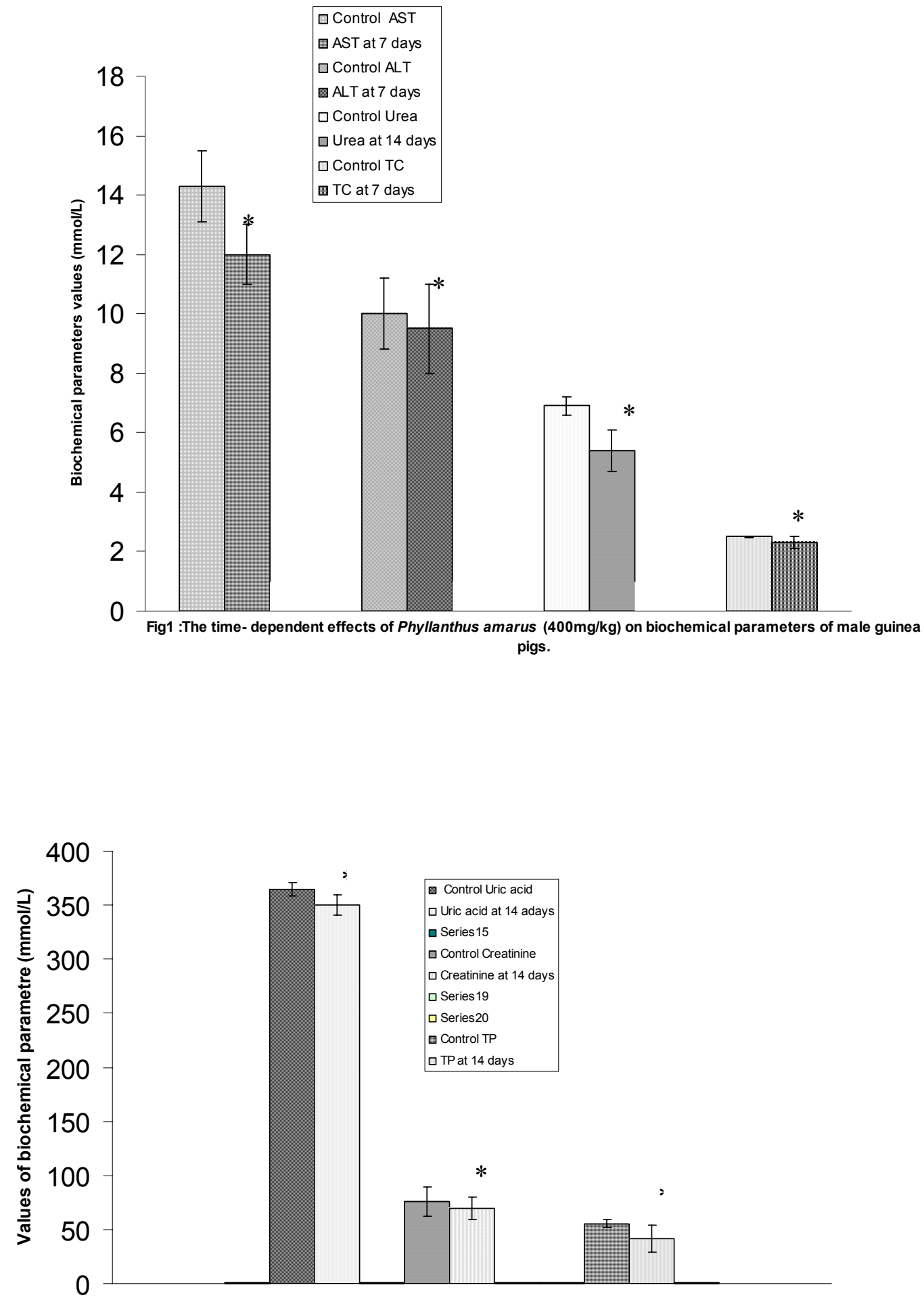

Fig 2: The effect of Phyllanthus amarus on the Uric acid, Creatinine and total protein on the male guinea pigs. 


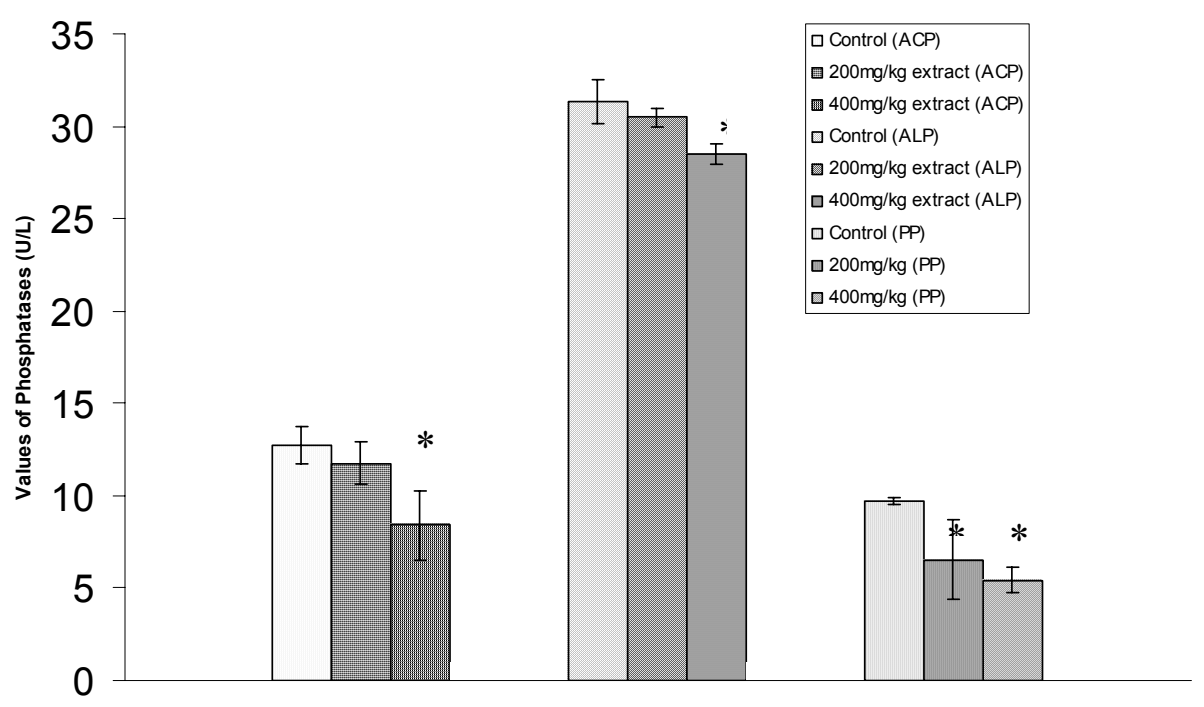

Fig 3: The dose-dependent effects of P.amarus on Acid, Alkaline and Prostatic phosphatases of male guinea pigs

This study shows that the methanolic extract of the leaf of Phyllanthus amarus causes a dose- and timedependent decreases in the biochemical parameters such as: AST, ALT, Urea, Uric acid, Creatinine, Total cholesterol, Protein, Alkaline, Acid, and Prostatic Phosphatases (Fig I ,2 and 3).These effects were statistically significant at $\mathrm{P}<0.05$ using student t-test.

By reducing the total cholesterol levels, it indicates that this plant can exert anti-diabetic, antihypertensive, and anti- lipidemic properties. This is consistent with the past works of Adeneye et al., 2006. By lowering the levels of AST, ALT, Phosphatases and Creatinine, it indicates that $P$. amarus has hepatoprotective and nephro-protective effects. This is also consistent with the past works of Adeneye et al., (2006).

The Uric acid, total cholesterol and protein lowering effect of these plants indicate that the plant can have anti-hypertensive, anti-inflammatory and antinociceptive effects. This is also consistent with the past works (Kasuya et al., 2003; Adeneye et al., 2006).

This study therefore ascertains the claims on the folkloric use of Phyllanthus amarus as a hepatoprotective and nephroprotective agent. It also supports the potentials of the plant as anticarcinogenic, anti-lipidemic, analgesic and antiinflammatory agent. Further studies are on the way to isolate, identify and characterize the active principles in the leaf of P.amarus, as well as identification of mechanism of action of Phyllanthus amarus.

\section{REFERENCE}

Adeneye, A A; Benebo, A S; Agbaje, E O (2006). Protective effect of the Aqueous Leaf and seed Extract of Phyllanthus amarus on Alcohol induced hepatotoxity in rats. West Afr. J. Pharmacol. Drug Res. 22\&23:42-50

Adeneye A A; Amole, O O; Adeneye, A K (2006). The hypoglycemic and hypocholesterolemic activities of the aqueous leaf and seed extract of Phyllanthus amarus in mice. Fitoterapia. 77: 511-514.

Babson, L A; Greeley, S J; Coleman, C M; Phyllips, G D (1966). Phenolphthalein Monophosphate as a substrate for serum alkaline phosphatase Clin. Chem. 12: 482-490.

Fishman H William; Davison M Harold (2006). Determination of serum acid phosphates method. Biochemical Analysis 4: 257-284.

Iwu, M M (1993). Modalities of drug administration. In: Hand book of African Medicinal Plants. CRC Press Inc. Florida. 309- 330.

Joy, K L; Kuttan, R (1998) Inhibition by Phyllanthus amarus of hepatocarcinogenesis induced by $\mathrm{N}$ Nitrosodiethylamine. J. Bioch. Nutr. 24: 133139.

Kassuya, C A; Silerstre, A A; Rehder, V; Calixto J B (2003). Anti allodynic and antioedematogeni 
properties of the lignan from Phyllanthus amarus in models of persistent inflammatory and neuropathic pain Eur. J Pharm . 478: 145-153.

Kokwaro, J O (1976). Medicinal Plants of East Africa Literature Bureau. 95

Meixa, W; Haowei, C; Yanji, L (1995). Herbs of the genus phyllanthus amarus in the treatment of chronic hepatitis B: Observation with three preparations from different geographical sites. J. Lab. Clin. Med.126:350-352

Odebedy O; Sofowora (1978). Phytochemical screening of Nigerian medicinal plants Lloydia 41: 41-234.

Odetola, A A; Akkojenu S M (2000). Antidiarrhoeal and gastrointestinal potentials of the aqueous extracts of Phyllanthus amarus (Euphorbiaceae). Afri. J.Med. Sci.29: 119-122.

Okwu, DE (2004). Phytochemicals and vitamin content of indigenous spices of Southern Nigeria J. Sustain. Agric. Environ. 6(1): 30-37.
Okwu DE; Josiah, C (2006) .Evaluation of the chemical composition of two Nigerian medicinal plants. African Journal of Biotechnology vol 5 (4): $357-361$.

Sofowora, A (1993). Medicinal Plants and Traditional Medicine in Africa.

Spetrum books.

Stray, F (1998). The Natural Guide to Medicinal Herbs and Plants.

Tiger Books International, London p. 12-16.

Thyagarajan S P; Subramanian, S; Thirunalasundar, T (1988). Effects of Phyllanthus amarus on the chronic carriers of hepatitis B virus. Lancet 2: 764-766.

Trease, G E; Evans W.C (1989). Trease and Evans Pharmacognosy.

A physician guide to Herbal medicine $13^{\text {th }}$ edition: Ballere tindal London 